\title{
Input Providing vs. Output-Prompting Negotiation Strategies in Learning Grammar among Young EFL Learners
}

\author{
Khorshid Mousavi \\ Urmia University, Iran, kh.mossavi@gmail.com \\ Parviz Alavinia \\ Asst. Prof., corresponding author, Urmia University, Iran, pevinia2006@gmail.com \\ Javad Gholami \\ Asst. Prof., Urmia University, Iran,j.gholami@urmia.ac.ir
}

\begin{abstract}
The present study investigated the comparison between short and long-term effectiveness of input-providing and output-prompting negotiation strategies on mastering the target structures. To this end, the participants were divided into three groups, namely two experimental groups who had a special kind of treatment, and one control group without any treatment. The participants within the first experimental group received either recasts or confirmation checks as inputproviding strategies on errors, whereas the other experimental group participants were exposed to the other types of feedbacks under the category of output prompting strategies and prompts during 10 sessions of teacher-learner interactions with 54 young EFL learners. In addition, the other focus of the study was on the uptake following the above-mentioned strategies. The results revealed a significant difference among the groups under investigation in this study related to grammaroriented uptake rates, because the rates of input-providing and output prompting classes were more than those of no feedback group. In addition, output-prompting group outperformed input-providing and control group in terms of grammar learning and retention in both short and long runs. The findings of the present study show that teachers could employ both input- and output-providing strategies judiciously and both seem to be effective.
\end{abstract}

Keywords: corrective feedback, grammar learning, input-providing strategy, outputprompting strategy, learning

\section{INTRODUCTION}

English classrooms are complicated places where everybody can observe lots of interactions among learners and teacher. Within classrooms as social environments (Tudor, 2001) with typically one instructor and a number of students, negotiation of

Citation: Mousavi, K., Alavinia, P., \& Gholami, J. (2018). Input Providing vs. Output-Prompting Negotiation Strategies in Learning Grammar among Young EFL Learners. International Journal of Instruction, 11(2), 497-512. https://doi.org/10.12973/iji.2018.11234a 
meaning and form to gain acquisition is of prime importance. As a matter of fact, negotiation strategies and interaction in instructional settings are embedded into the vast area of error treatment or corrective feedback $(\mathrm{CF})$ in communicative-oriented contexts.

Simultaneous with the history of error treatment, from the survey of various approaches and methods in Second Language Acquisition (SLA) research, the history of interaction in meaning-focused instructions gained significant importance in learning a second language (L2). Among the scholars who studied the role of interaction, a reference can be made to Hatch (1978) who focused narrowly on the role of input as well as interaction. She claimed (1978, p.404, as cited in Ellis, 2008): "One learns how to do conversations, one learns how to interact verbally, and out of this interaction syntactic structures are developed". Long (1981, 1983, 1996) continued Hatch's studies and became well-known by his interaction hypothesis.

The hypothesis claims when L2 learners interact with each other or with native speakers, they try to use a series of interactional techniques and adjustments to make the communication comprehensible and to negotiate the meaning (Schmitt, 2002) through comprehension checks, confirmation checks and repetition. In two versions of interaction hypothesis (early and later versions), Long simply postulated a role for comprehensible input but in the later version, he was more faithful to the earlier work of Hatch in which he acknowledged that interaction can facilitate acquisition by assisting learners' L2 production. The later version of the hypothesis has also been closely associated with another construct-focus on form or FonF (Ellis, 2008) as a basis for attention to the linguistic forms within meaning-oriented activities (Long, 1991) in which activities, negotiation exchanges are accomplished through negotiation strategies (Ellis, 2008) that can be classified in terms of being explicit and implicit (Ellis, Leowen \& Erlam, 2006) or input providing and output-prompting (Ellis, 2008).

Based on the above-mentioned taxonomy, recasts and confirmation checks as corrective feedback types have fallen in the area of input providing negotiation strategies since they provide learners with input, and the other types of feedback strategies i.e., clarification request, elicitation, repetition, explicit correction, metalinguistic feedback, labelled prompts (Lyster, 2004), are subcategorized into the big category of outputprompting strategies. Input providing and output-prompting strategies under the category of recasts and prompts have been studied from the heydays of error treatment up to the present time by different researchers (Kamiya, 2015; Lyster, 2004; Takahashi, 2014; Yang \& Lyster, 2010).

Nevertheless, there are still some aspects of different feedback types such as input providing and out-put-prompting strategies which have been neglected to a large extent. This study explored the effectiveness of input providing versus output-prompting negotiation strategies on grammatical gains of young EFL learners in the short and long run. In addition, the study was an attempt to explore the existence of any significant difference in the grammar-oriented uptake rates (immediate response to $\mathrm{CF}$ ) following input providing and output-prompting negotiation strategies in Iranian young EFL learners' classes. 


\section{LITERATURE REVIEW}

\section{Input-providing negotiation strategies}

Corrective feedback is regarded as a vital part of form-focused instruction (FFI) when the teacher tries to react against the learners' committed errors. When the teacher responds to the students orally, it is regarded as "Oral CF" (Gooch, Saito \& Lyster, 2016). There is a bulk of research investigating the CF types to bold the effectiveness of one type over the others within the processes of SLA (they mostly have focused on recasts versus prompts). In the current study recasts and confirmation checks were equated with input-providing negotiation strategies and prompts were equated with output prompting negotiation strategies. Recast is an input-based corrective feedback and the learners are provided with some correct forms of input and the learners are not pushed to modify the incorrect responses and they are not supposed to produce a correct form of output (Rassaei, 2015).

In terms of the first category, some studies have looked at recasts from different perspectives such as intensive and extensive recasts, but their effectiveness is still fraught with uncertainty (Ammar \& Spada, 2006; Erlam \& Loewen, 2010; Goo, 2012; Kamiya, 2014; Loewen \& Nabei, 2007; Loewen \& Philp, 2006; Maftoon \& Kolahi, 2009; Rassaei, 2015). For instance, Kamiya (2014) in a study explored the effectiveness of intensive and extensive recasts on the acquisition of a planned target structure with 44 ESL language learners. The experimental groups had intensive recasts on errors regarding unreal conditional sentences for the first group, and extensive recasts regarding all the committed errors for the second group. The findings of the study showed that the experimental groups had higher performances with better improvements in the accuracy levels juxtaposed with the control group.

\section{Output prompting negotiation strategies}

In terms of the second category or output prompting strategies, lots of studies (e.g., Gholami \& Aliyari, 2016; Loewen \& Philp, 2006; Lyster, 2004; Lyster \& Izquierdo, 2009) have been conducted so far both in ESL and EFL contexts.

From the chronological point of view, form-focused instruction, and its effect on French immersion young learners' acquisition of grammar across gender was explored by Lyster (2004). It was found in his study that prompts provided a better situation for the learners in order to significantly get better promotions juxtaposed with recasts. It is worth mentioning that prompts were of higher values in written format but not in oral forms. He noticed that the nature of the tasks causes the level of promotion to happen for oral production (which is less than written production).

In another study by Yang and Lyster (2010), different impacts of prompts, recasts, and non-CF were compared and contrasted regarding regular and irregular past-tense by Chinese EFL students. The results of the administered tests indicated that the scores of prompt groups outperformed in comparison with recast groups when using the past tense forms under investigation in the study. Similar impacts were seen for both recasts and prompts when the accuracy of the learners was the focus of the study. In contrast, 
Ammar and Spada's study (2006) showed that the effectiveness of recasts and prompts was affected by the students' pretest scores. That is, when they had higher scores in their pretest, recast were found to be as effective as prompts, but by the time their pretest scores were in a lower position, and prompt groups outperformed the recast groups.

Form-focused instruction has been investigated by many scholars (e.g. Ellis, 2012; Lyster, Saito \& Satio, 2013; Sheen, 2011). They concordantly reached a similar result that $\mathrm{CF}$ was highly effective juxtaposed with classes without $\mathrm{CF}$. In the same vein, the language learners were also reluctant to omit $\mathrm{CF}$ in their classes; they also preferred prompts over recasts (Doughty \& Varela, 1998).

From this brief overview of the literature and to the best knowledge of the researcher, no study has compared the effectiveness of input providing negotiation strategies with output-prompting negotiation strategies. Therefore, our knowledge of the effectiveness of these types of FFI is premature. Therefore, to provide us with more information about the effectiveness of input providing negotiation strategies with output prompting negotiation strategies and to contribute to EFL teachers' understanding of the potential differential effects of those methods on grammatical gains of young learners, the present study attempted to investigate the effectiveness of these two approaches in an EFL context. To this end, it made use of short-term and long-term retention measurements to provide us with more fruitful findings. In addition, it explored the rates and frequencies of observational uptake moves occurring after input-providing and output-prompting strategies in young learners' classrooms. To this end, the following research questions were formulated:

1. Are there any significant differences in the grammar-oriented oral uptake rates following input-providing and output-prompting negotiation strategies in young EFL learners' classes?

2. Do input-providing and output-prompting negotiation strategies have any significant effects on young EFL learners' grammar learning in short and long terms?

3. Are there any significant differences in the relative effects of input-providing and output-prompting negotiation strategies on young EFL learners' grammar learning in short and long terms?

\section{METHOD}

\section{Research design}

Regarding the design of the study, the mixed methods research design (qualitative and quantitative) was applied in this study. In order to collect the required quantitative and numerical data for the present study, the young learners participated in input-providing and output-prompting experimental groups as well as no feedback as control group to investigate any possible impacts of the two FFI options. Then, the young learners from groups were measured in terms of dependent variables before treatment. Very similar to all of the studies containing treatment, input-providing and output prompting strategies were given to learners as treatments in experimental groups to measure the effectiveness of those negotiation strategies while the control group receives placebo (Büyüköztürk, et al., 2009). 
For the aim of gathering qualitative data, the data contained learner-teacher formfocused episodes within each error-treatment move, and learners' immediate response to their teachers' corrective feedback coded as uptake were collected by the researcher after audio-recording of the classes and transcribing uptake moves. This section of data collection goes back to research question number one which was an attempt to investigate the existence of any significant difference in the grammar-oriented uptake rates following input providing and output-prompting negotiation strategies in Iranian young EFL learners' classes.

\section{Participants}

The sample of the current study consisted of approximately 64 learners with elementary level of proficiency studying at a private Language Institute in Iran, Tabriz. The participants were female learners ranging in age from 9 to 13 with Turkish as their L1. Subsequent to running the homogeneity test, the researchers divided the remaining participants (54 students) to three experimental groups as well as a control group. Furthermore, three experienced female teachers within the board of the institute were selected as the instructors of the classes. The teachers received instruction from the researchers on what and how to give feedback based on the classes they were teaching. It is worth mentioning that the students were selected by convenience sampling and based on availability.

\section{Data collection instruments}

In order to achieve the goals of the study, various instruments were used by the researchers: Young Learners English (YLE) proficiency test to homogenize EFL learners' level of language proficiency, pretest, immediate posttest and delayed posttest to investigate the short-term and long-term effectiveness of the treatment and audiorecording of classrooms to gather more valuable data from the classes regarding the observable uptake.

Initially, a proficiency test was run in order to check the learners' general English knowledge. For the aim of the study, YLE movers was selected. The test was administrated two sessions before the onset of the study. After scoring the results of YLE, with the criterion of one standard deviation plus and minus the mean, 54 female EFL learners were chosen as the final participants of the study from the total of 64 learners and 10 of them were dropped due to their high or low scores in the test.

The other instrument in the current study was a pretest to check the young learners' knowledge of the target features and to see if there was a significant difference among them with regard to their knowledge of the target features that were covered in the classroom. Immediate posttest and delayed posttest were the other data collection tools for measuring the short-term effectiveness and long-terms retention of input-providing and output-prompting strategies on grammar learning. In this study, the focus was on the grammatical points and the textbook under study (Hip Hip Hooray (1B)) contains different grammatical points such as yes/no questions, wh-questions, prepositions, and do/does questions. Based on the content of the textbook and the grammar points covered during treatment, the tests were designed. The tests were the same in order to ensure 
comparability. They were in the form of both multiple-choice and recognition test (Part A) and written test and production test (Part B) with 20 items in multiple-choice format from the three grammatical rules that were covered in the treatment, 10 written items in the form of completion task and 10 items from the previous semesters with which the students already were familiar, but the researcher did not regard the scores for those 10 items. The total number of items in the tests was 40 and the allotted time for tests was 45 minutes. Considering the important role of validity, the test had been expert-judged by three experts in the assessment board of the institute. The panel of experts reported acceptable validity. The reliability of the test was reported to be .79 .

Finally, the classes were audio-recorded by the researcher to obtain the observableuptakes after input-providing and output-prompting strategies as reactions to learners' errors. The data contained learner-teacher form-focused episodes within each errortreatment move as well as learners' immediate response to their teachers' feedbacks in the form of input-providing and output-prompting strategies coded as uptake.

The following extracts from the study clarify the explanations. The first extract was taken from input-providing group which led to uptake.

\section{Extract 1:}

$\mathrm{T}$ : how old is your brother?

S: I have 35 years old.

$\mathrm{T}$ : your brother [rising tone]

$\mathrm{T}$ : he is 35 [uptake]

In this extract, the teacher in input-providing treatment class asks a question and in response to students' erroneous production, she uses a rising tone as a trigger to warn the student of the error and finally in the last move, the uptake happens successfully by the student. The second extract was chosen from output-prompting classroom again with uptake move.

Extract 2:

T: Parastoo, when do you go home?

S: I go home by car

T: When do you go home?

S: oh yes...I go home at 1 o'clock.

In this extract, the teacher uses the strategy of repetition and puts high stress on the word 'when' to attract the attention of the learner to the occurrence of error. As a result of attention getting, the learner understands the existence of error and corrects her own error with the uptake.

\section{Procedure}

The present study was an attempt to investigate any possible effects of input-providing and output-prompting FFI on learners' grammatical gains in young classes. The grammatical points to be tapped in this study included yes/no questions, wh-questions and prepositions that were covered in the textbook under study for the young EFL learners. Two weeks before the beginning of the study, students were homogenized 
based on the scores of YLE movers as one of the three tests of Cambridge English. The test that contains clear and lively pictures to test students' proficiency in different skills such as listening and reading was used since it is a suitable test for young learners with low level of proficiency in general English. The criterion for homogeneity of the learners was their scores based on one standard deviation above and below the mean. After this phase, In order to investigate any possible impacts of the two FFI options, the 54 homogenized learners from the total of 64 young learners were divided into three groups randomly. Accordingly, there were two experimental groups and one control group. These three groups of learners were instructed by experienced teachers with more than 8 years of teaching.

The experimental groups received either input-providing FFI or output-prompting FFI in correcting young learners' special grammatical errors such as yes/no questions occurring during teacher-learner interactions. The participants in the control group, however, received instruction in the form of no feedback on the errors occurring in the target forms. After homogenizing the learners, they were pretested by a grammar pretest as explained above in an isolated session before treatment. The time limit for the pretest was 45 minutes. The treatment started for 10 sessions after these phases. The process for treatment in the groups under study was as follows:

In the input-providing FFI group, the instruction on the target structures was embedded into communicative tasks. The young learners engaged in communicating with each other, and the teacher carefully observed them and provided them with corrective feedback through input-providing FFI on their errors in using the target structures. Corrective feedback through input-providing FFI means that learners' errors on the grammatical points taught at the classroom were corrected just by either recasts or confirmation checks that fall in the area of input-providing negotiation strategies since they are providing learners with input and not output (Ellis, 2016). There are a number of ways to categorize recasts; one of them is intensive and extensive recasts (Kamiya, 2015). According to Ellis (2001), intensive recasts occur when the target structure is planned in the lesson, and learners are likely to receive feedback so many times on a single, pre-selected structure. In contrast, extensive recasts occur when no target structure is selected by the teacher or researcher; nevertheless, learners receive feedback on many structures that occur incidentally during instruction. Based on this taxonomy, the instructor in this study was required to use both types of recasts (intensive and extensive) as a result of reaction to young learners' ill-formed utterances. However, the researchers limited grammar instruction and the analysis of the uptake moves only to phases and moves, including yes/no questions, wh-questions and prepositions and different strategies of feedback expected to be given. In this process, the teacher using recast sometimes raised her intonation to draw students' attention to the existence of errors. As stated above, confirmation check is a type of error-correction strategy that falls in the area of input-providing negotiation strategies (Ellis, 2008). The teacher in input providing FFI group was asked to correct young learners' errors by confirmation checks in addition to recasts. In confirmation checks, the teacher asked questions like 'so, what you mean is ...' (Hall, 2011) in order to see whether they had understood the message correctly. 
All of the tasks and instructions were the same for the output-prompting group except that the young learners' errors on the grammatical points were corrected by other types of strategies i.e., request for clarification, repetition, metalinguistic feedback, elicitation, and explicit correction, labelled prompts (Lyster, 2004), which in the current study are subcategorized into big category of output-prompting strategies. As a matter of fact, the difference between two experimental groups was in the types of reactions by the teacher to the learners' errors in the target forms under study. Finally, the participants in the control group received feedback only on content; it means that the instructor in the control group switched to focus on meaning, not focus on form and ignored the learners' grammatical errors.

It is worth mentioning that the treatment lasted for 10 sessions which was audiorecorded with two mini-sized mp3 voice recorders placed between the teachers and the learners to obtain audio-data from the whole class interactions. There was transcription of those moves accordingly by the researcher. A second rater coded $10 \%$ of the audiorecorded data, taken randomly from the ten sessions of instruction. The inter-rater reliability for the uptake moves was considered high at $91.6 \%$. After the treatments, two posttests in grammar were administrated to the learners based on the content of the textbook under study and the instructions that were given by the teachers. The pretest and posttests were piloted before the study by a limited number of participants from the same population (young EFL learners with the same age range at elementary level) to remove some items from the tests or to add the other items based on the results of the pilot study. The reason for using two posttests (i.e., immediate and delayed) was to investigate young learners' short-term and long-term retention of the instruction. The internal consistency of the tests and their inter-rater reliability was found to be 0.79 .

\section{Data analysis}

To find an answer to the first research question that investigated the difference in the uptake of treatment groups, Chi-square was run. To answer the second research question that was about the existence of any significant difference in the relative effects of inputproviding and output-prompting negotiation strategies on young EFL learners' grammar learning in the short and long run, a repeated measure ANOVA and one-way ANOVA were run to analyse gains in each group and across groups over time, respectively.

\section{FINDINGS}

The audio recordings of the instructional treatment sessions were transcribed and analysed to identify the number of errors in the use of special grammatical rules and immediate repair or uptake across different groups in order to explore the existence of any significant difference in the grammar-oriented uptake rates following input providing and output-prompting negotiation strategies among Iranian young EFL learners' classes. The first research question in this study was concerned with the exploration of uptake moves following the implantation of input providing and outputprompting negotiation strategies. Table 1 presents the results of uptake moves following the errors occurring in the groups under study. 
Table 1

Frequency and percentage of uptake moves in the groups

\begin{tabular}{llll}
\hline Groups & Errors F & Uptake F (\%) & No uptake F (\%) \\
\hline Input-providing & 110 & $68(61.8 \%)$ & $42(38.2 \%)$ \\
\hline Output-prompting & 133 & $83(62.4 \%)$ & $50(37.6 \%)$ \\
\hline No feedback & 89 & $33(37 \%)$ & $56(63 \%)$ \\
\hline Total & $332(100 \%)$ & $184(55.5 \%)$ & $148(44.5 \%)$ \\
\hline
\end{tabular}

As shown in Table 1, all three groups produced different numbers of errors followed by different rates of uptake during the treatment sessions. The number of errors covered by input-providing feedback was 110 out of the total, about $68(61.8 \%)$ of the feedbacks led to uptake and $42(38.2 \%)$ of them was ignored by the students; the numbers of errors containing feedback in the output-prompting group was 133 out of which the learners' response in the form of uptake was $83(62.4 \%)$ and finally, the numbers of errors including no feedback on the target forms in the control group was 89 out of the total, just $33(37 \%)$ of which led to uptake. The results of Chi-square analysis on the distribution of uptake moves and no uptake moves revealed that there is a significant difference among group $\left(\chi^{2}=17.82 ; d f=2 ; p\right.$ value $\left.=0.0001, p<0.05\right)$. In other words, depending on the types of feedback instruction in young learners' classes, observable uptake rates were found to differ across groups significantly. Uptake took place in output-prompting and input-providing groups more than twice as many as it did in the no-feedback group. When the two experimental groups were compared, despite the observable discrepancy between the uptake rates, Chi-square analysis did not provide any significant difference between them $\left(\chi^{2}=0.1 ; d f=1 ; p\right.$ value $\left.=0.75, p>0.05\right)$.

The second research question dealt with the effectiveness of input-providing and outputprompting negotiation strategies per se on young EFL learners' grammar learning in short and long terms. Prior to comparing the gains in the groups, the normality of the data was checked through Shapiro-Wilk which yielded a normal distribution. Thus, parametric tests were used to compare the performance of the groups per se and across them. The descriptive findings for the use of target forms under study for each group across time are displayed in Table 2.

Table 2

Descriptive Statistics of Groups across Time

\begin{tabular}{llllllllll}
\hline \multicolumn{1}{c}{ Pre-test } & \multicolumn{1}{c}{ Immediate Posttest } & \multicolumn{3}{c}{ Delayed Posttest } \\
\hline & $\mathrm{N}$ & $\mathrm{M}$ & $\mathrm{SD}$ & $\mathrm{N}$ & $\mathrm{M}$ & $\mathrm{SD}$ & $\mathrm{N}$ & $\mathrm{M}$ & $\mathrm{SD}$ \\
\hline Input-providing & 18 & 6.88 & 1.49 & 18 & 15.55 & 2.5 & 18 & 15.66 & 1.74 \\
\hline Output-prompting & 18 & 6.66 & 1.53 & 18 & 17.33 & 2.22 & 18 & 17.88 & 1.67 \\
\hline Control & 18 & 6.55 & 1.78 & 18 & 11.66 & 1.97 & 18 & 12.27 & 1.52 \\
\hline
\end{tabular}

As it is evident from this table, the means of groups are roughly the same at pretest, while they are different in the immediate and delayed posttests. Since the participants in each group took the test three times (pretest, immediate and delayed posttests), the researchers decided to run repeated measures of ANOVA in order to investigate the gains from pretest to immediate and delayed posttests. In so doing, three repeated measure ANOVA tests were run for pretest, immediate posttest and delayed posttest. 
Table 3 shows the results of within-subject effect for the first group, that is inputproviding group.

Table 3

Tests of Within-Subject Effects for Input-providing Group

\begin{tabular}{|c|c|c|c|c|c|c|c|}
\hline Source & & $\begin{array}{l}\text { Type III Sum } \\
\text { of Squares }\end{array}$ & df & $\begin{array}{c}\text { Mean } \\
\text { Square }\end{array}$ & $\mathrm{F}$ & Sig. & $\begin{array}{l}\text { Partial Eta } \\
\text { Squared }\end{array}$ \\
\hline \multirow[t]{4}{*}{ Time } & Sphericity Assumed & 913.037 & 2 & 456.519 & 152.727 & .000 & .900 \\
\hline & Greenhouse-Geisser & 913.037 & 1.334 & 684.640 & 152.727 & .000 & .900 \\
\hline & Huynh-Feldt & 913.037 & 1.405 & 650.039 & 152.727 & .000 & .900 \\
\hline & Lower-bound & 913.037 & 1.000 & 913.037 & 152.727 & .000 & .900 \\
\hline \multirow{4}{*}{$\begin{array}{l}\text { Error } \\
\text { (Time) }\end{array}$} & Sphericity Assumed & 101.630 & 34 & 2.989 & & & \\
\hline & Greenhouse-Geisser & 101.630 & 22.671 & 4.483 & & & \\
\hline & Huynh-Feldt & 101.630 & 23.878 & 4.256 & & & \\
\hline & Lower-bound & 101.630 & 17.000 & 5.978 & & & \\
\hline
\end{tabular}

From Table 4, the $F$ value for the "time" factor, its associated significance level and effect size ("Partial Eta Squared") can be discovered. Since the assumption of sphericity was violated, it is necessary to look at the values in the "Greenhouse-Geisser" row. Therefore, for ANOVA with repeated measures with a Greenhouse-Geisser correction, the mean scores for grammar learning concentration were statistically significantly different $(F(1.33,22.67)=152.72, p<0.0001)$. Table 4 only reveals that there are significant differences between the three occasions (pretest, immediate posttest, and delayed posttest); however, in order to find out where this difference lies, there is a need to report pairwise comparison table, which is the Boneferroni post hoc test. Table 4 shows the results of pairwise comparisons for the input providing group.

Table 4

Pairwise comparisons for input-providing group

\begin{tabular}{|c|c|c|c|c|c|c|}
\hline \multirow{2}{*}{$\begin{array}{l}\text { (I) } \\
\text { Time } \\
\end{array}$} & \multirow{2}{*}{$\begin{array}{l}\text { J }) \\
\text { Time }\end{array}$} & \multirow{2}{*}{$\begin{array}{l}\text { Mean } \\
\text { Difference (I-J) }\end{array}$} & \multirow{2}{*}{$\begin{array}{l}\text { Std. } \\
\text { Error }\end{array}$} & \multirow[t]{2}{*}{ Sig. ${ }^{a}$} & \multicolumn{2}{|c|}{$95 \%$ Confidence Interval for Difference ${ }^{a}$} \\
\hline & & & & & Lower Bound & Upper Bound \\
\hline \multirow[t]{2}{*}{1} & 2 & $-8.667^{*}$ & 714 & .000 & -10.562 & -6.771 \\
\hline & 3 & $-8.778^{*}$ & .613 & .000 & -10.406 & -7.149 \\
\hline \multirow[t]{2}{*}{2.} & 1 & $8.667^{*}$ & 714 & .000 & 6.771 & 10.562 \\
\hline & 3 & -.111 & 332 & 1.000 & -.993 & .771 \\
\hline \multirow[t]{2}{*}{3} & 1 & $8.778^{*}$ & .613 & .000 & 7.149 & 10.406 \\
\hline & 2 & .111 & 332 & 1.000 & -.771 & .993 \\
\hline
\end{tabular}

Based on estimated marginal means

*. The mean difference is significant at the .05 level.

a. Adjustment for multiple comparisons: Bonferroni.

1. Pretest 2. Immediate posttest 3. Delayed posttest

As is clear from Table 4, for the input-providing group, the difference is significant from pretest to immediate posttest and also from pretest to delayed posttest $(p<0.05)$. However, from the immediate posttest to delayed posttest, the difference is not significant $(p>0.05)$. The same procedure has been done for the output-prompting group. It's worth noting that in what follows, for the sake of brevity and sticking to 
journal word limit, only the explanations of tables regarding repeated measure ANOVAs for output-prompting and control group are provided.

As the results revealed, there are significant differences between the three occasions (pretest, immediate posttest, and delayed posttest) in the output-prompting group; furthermore, it is found that there are significant differences among the three occasions (pretest, immediate posttest, and delayed posttest) in the no feedback group. Then, the second null hypothesis that claimed there is no significant difference in the relative effects of input-providing and output-prompting negotiation strategies on young EFL learners' grammar learning in the short and long run was rejected and the results showed that output-prompting group outperformed input-providing and no feedback groups in terms of grammar learning across time.

The third objective of this study was concerned with investigating the relative effects of input-providing and output-prompting negotiation strategies on young EFL learners' grammar learning in the short and long run. One-way ANOVA was run to test the gain differences across the groups. Table 5 shows the results of one-way ANOVA of the tests.

Table 5

Results of One-Way ANOVA

\begin{tabular}{cllllll}
\hline Tests & & Sum of Squares & df & Mean Square & F & Sig. \\
\hline \multirow{2}{*}{ pre } & Between Groups & 1.037 & 2 & .519 & .200 & .819 \\
\cline { 2 - 7 } & Within Groups & 132.222 & 51 & 2.593 & & \\
\cline { 2 - 7 } & Total & 133.259 & 53 & & & \\
\hline \multirow{2}{*}{ Post1 } & Between Groups & 302.370 & 2 & 151.185 & 30.067 & .000 \\
\cline { 2 - 7 } & Within Groups & 256.444 & 51 & 5.028 & & \\
\cline { 2 - 7 } & Total & 558.815 & 53 & & & \\
\hline \multirow{2}{*}{ Post2 } & Between Groups & 287.444 & 2 & 143.722 & & \\
\cline { 2 - 6 } & Within Groups & 139.389 & 51 & 2.733 & & \\
& Total & 426.833 & 53 & & & \\
\end{tabular}

Regarding pre-test, it is worth mentioning that since the $p$-value is $.819 \geq 0.05$, it can be said that the groups are homogeneous before treatment, $\mathrm{F}(2,51)=.200, p=.819$, but in immediate posttest $p$-value is $.000 \leq 0.05$, and it can be said that the groups are different from each other after treatment, $\mathrm{F}(2,51)=.30 .06, p=.000$. In fact, experimental group learners outperformed in grammar learning in the short run. Like immediate posttest, in delayed posttest, the three groups were different since $p$-value is $.000 \leq 0.05, \mathrm{~F}(2,51)=$ $.52 .8, p=.000$. In order to know where the differences are, post hoc tests were run in both immediate posttest and delayed one.

As the results of post-hoc analysis revealed, there was a significant difference among the three groups on both immediate and delayed posttests. Consulting the descriptive data in Table 2, it can be concluded that input-providing and output-prompting groups have both made a better improvement compared to control group in terms of grammar retention based on the immediate and delayed posttest results. However, the performance of output-prompting group is witnessed to be better than the other two groups on both immediate and delayed posttests. 


\section{DISCUSSION}

As stated before, the aim of the present study was to explore the existence of any significant difference in the grammar-oriented uptake rates following input-providing and output-prompting negotiation strategies as well as no feedback group as the control group in Iranian young EFL learners' classes. Furthermore, the study aimed at discovering the effectiveness of the above-mentioned strategies on grammar performance of specific target forms (wh- and yes/no questions and prepositions) in the short and long runs. Based on the findings in Table 1, the type of negotiation strategies, that is input-providing and output-prompting strategies, was found to have a significant difference on the observational uptake rates and the rates of uptake at input-providing and mostly at output-prompting classes were more than those of no feedback group.

In order to answer the second research question, a repeated measure ANOVA was run and based on the findings from Tables 2 to 9, its results represented that outputprompting group outperformed input-providing and no feedback groups in terms of grammar learning in the short and long run.

One justification for the higher effectiveness of output-prompting strategies or prompts both in orally observed uptake moves as well as in posttests can be attributed to their endemic nature. As Extract 1 illustrated, in output-prompting strategies, the teacher pushes language learners in order to make them retain language forms which have been learnt and saved in long-term memory. In addition, as pointed out by Ellis (2016), the necessity of producing output after output-prompting strategy obliges learners to produce more uptake and in fact be more sensitive to their own production. Such a requirement is less in place in the case of input-providing negotiation strategies. It seems quite plausible to assume that uptake moves on the part of learners in prompts look more to be an obligatory one, whereas in input-providing ones, such moves tend to be more optional and the learner is less compelled to take this move or could simply ignore it. This may account for the highest frequency of uptake moves in classes and the highest gains of the group receiving out-prompting negotiation strategies in the posttests.

When comparing input-providing strategy with no feedback group, we find that inputproviding group outperformed no feedback group in grammar learning, even though the impact of input-providing was less than output-prompting strategy. The reason can go back to the fact that the teacher in input-providing group mostly used feedbacks in the form of implicit correction (recast) and low age of the learners of the current study hindered them from clearly getting the correct target form. Based on the analysis of the audio-recordings from teacher-learner interactions, there were occasions when the learners in the input-providing group were baffled with the type of feedback or strategy and finally after repetitions of feedback in teacher's turn, the students produced the correct form of the grammar. Extract 3 demonstrates such a presumably confusing focus on form episode:

Extract 3:

$\mathrm{S}$ : Does your mom's name is Sara?

S: No she doesn't 
$\mathrm{T}$ : A problematic issue, let's write it on the board

Teacher wrote the incorrect sentence of ' Does your mom's name is Sara? 'on the board.

$\mathrm{T}$ : Correct the sentence, it is incorrect

$\mathrm{S}$ : Does your mom's name Sara?

S: What's your mom name?

$\mathrm{T}$ : In these type of sentences, you should omit one.

S: Your mom's name is Sara?

$\mathrm{T}$ : This is a statement not a question.

S: Is your mom's name Sarah?

$\mathrm{T}$ : Yes finally, excellent

As is clear from the extract, the teacher involved the student through the outputprompting strategy to learn the special target form in a correct manner and avoid using two question marks in one sentence.

The findings of the current study are in line with some previously conducted studies (e.g. Ammar \& Spada, 2006; Lyster, 2004; Lyster \& Mori, 2006). For example, Lyster and Mori (2006) stated that form-focused instruction in general and prompts in particular are effective in language classrooms, but teachers can use recasts as one major type of input-providing strategies in highly form-focused classrooms. In contrast, they can use prompts (equated with output-prompting strategies in the current study) in classrooms that are more meaning-focused. The finding can also be attributable to the nature of the learners and the target structures. In other words, some learners appear to be more receptive to prompt than recasts, and that some structures seem more amenable to prompts than recasts. Of course, this issue warrants further research. Given the design of this very study and its focus on some target forms such as wh-questions, these findings can be added to other studies which have been done to clarify the impact of different types of feedback on various language forms.

Although the present study was subject to some limitations such as test items that should be more than the number administered in this very study, actually, future body of research should juxtapose output-prompting strategies in all dimensions, either related to one another or to recasts and its various types, taking into consideration different types of language forms as well as learner differences. The differences in the language learners may be related to aptitude and the ability to analyse the language (Sheen, 2007), working-memory (Trofimovich, Ammar \& Gatbonton, 2007), and proficiency (Ammar \& Spada, 2006).

As for the implications of the study, this study supports the notion that pedagogical approaches to correcting grammar in Iran need special attention since this area of teaching English is very important in EFL process. This research was conducted to indicate the importance of negotiation strategies, and output prompting as one of the strategies was found to be very helpful in improving grammatical accuracy of the L2 learners. The implications of this study can be helpful for the use of language teachers who can employ output-prompting strategy more in their classes for improving 
grammatical accuracy of the learners. Teacher trainers can also instruct the teachers how to use focus on form options in teaching process and encourage them to draw more attention to output-prompting ones along with other focus on form interventions. Material designers can prepare materials that encourage teachers and learners to use output-prompting strategy in the classroom based on students' level of knowledge and their individual differences. Also, as a comprehensive and comparative study, the research can help EFL teachers be aware of the nature of the errors and usefulness of corrective feedback as a useful device to lead their students to enhance linguistic competence.

\section{CONCLUSION}

Focus on form, in general, and negotiation strategies, in particular, have gained a critical place in language education for different reasons. One of them can be the fact that they have become one of the choices that instructors can make, and the other is that negotiation strategies are considered by some scholars one of the prime factors of effective teaching (Grim, 2008). It is noteworthy that learners' needs and their preferences are the most important decisions of a teacher in choosing negotiation strategies in instructional settings. The current study illustrated that such decisions may make a difference in learning special target forms such as wh-questions, yes/no questions, and prepositions. The rate and frequency of observational uptake after feedback in the forms of input-providing, output-prompting and no feedback group was the first focus of the study. This study found statistically significant differences in the rates of uptake after the strategies under the study and its distribution was at its highest in output-prompting group. The present study also investigated the effectiveness of input-providing and output-prompting negotiations in learning special grammatical forms across time. The findings revealed that output-prompting was more effective in learning target forms both in the short and long terms. The negotiation strategies studied in this study warrant much additional examination not exclusively for future research related to big area of focus on form but also for studies in the field of second language acquisition since different types of instruction may evoke different patterns of development.

\section{REFERENCES}

Ammar, A., \& Spada, N. (2006). One size fits all? Recasts, prompts, and L2 learning. Studies in Second Language Acquisition, 28, 543-574.

Doughty, C., \& Varela, E. (1998). Communicative focus on form. In C. Doughty, \& J. Williams (Eds.), Focus on form in classroom second language acquisition (pp. 114138). New York, NY: Cambridge University Press.

Ellis, R. (2001). Introduction: Investigating form-focused instruction. Language Learning, 51, 1-46.

Ellis, R. (2008, 2nd ed.). The Study of Second Language Acquisition. Oxford: Oxford University Press. 
Ellis, R. (2012). Language teaching research and language pedagogy. West Sussex, UK: Wiley-Blackwell.

Ellis, R. (2016). Focus on form: A critical review. Language Teaching Research, 20(3), $1-24$.

Gholami, J., \& Aliyari, S. (2015). The impact of planned preemptive focus on form on Iranian EFL learners' essay writing ability. International Journal of Pedagogies and Learning, 10(3), 234-245.

Gooch, R., Saito, K., \& Lyster, R. (2016). Effects of recasts and prompts on second Language pronunciation development: Teaching English /r/ to Korean adult EFL learners. System, 60, 117-127.

Grim, F. (2008). Integrating focus on form in L2 content-enriched instruction lessons. Foreign Language Annals, 41(2), 321-346.

Hall, G. (2011). Exploring English language teaching, language in action. New York: Routledge.

Hatch, E. (1978). Acquisition of syntax in a second language. In J. Richards (Ed.), Understanding second and foreign language learning (pp. 34-70). Rowley, MA: Newbury House.

Kamiya, N. (2015). The effectiveness of intensive and extensive recasts on L2acquisition for implicit and explicit knowledge. Linguistics and Education, 29, 5972.

Krashen, S. (1981). Second language acquisition and second language learning. Oxford: Pergamon Press.

Loewen, S., \& Nabei, T. (2007). Measuring the effects of oral corrective feedback on L2 knowledge. In A. Mackey (Ed.), Conversational interaction in second language acquisition: A collection of empirical studies (pp. 361-376). Oxford: Oxford University Press.

Loewen, S., \& Philp, J. (2006). Recasts in the adult English L2 classroom: Characteristics explicitness, and effectiveness. Modern Language Journal, 90(4), 536556

Long, M. (1991). Focus on form: A design feature in language teaching methodology. In K. de Bot, R. Ginsberg, \& C. Kramsch (Eds.), Foreign language research in crosscultural perspective (pp. 39-52). Amsterdam: Benjamins.

Long, M. H. (1983). Native speaker/non-native speaker conversation and the negotiation of comprehensible input. Applied Linguistics, 4(2), 126-141.

Long, M. H. (1996). The role of the linguistic environment in second language acquisition. In C. Ritchie, T. K. Bhatia (Eds.), Handbook of language acquisition, vol. 2. Second Language Acquisition (pp. 413-468). New York: Academic press. 
Lyster, R. (2004). Differential effects of prompts and recasts in form-focused instruction. Studies in Second Language Acquisition, 26(3), 399-432.

Lyster, R., \& Izquierdo, J. (2009). Prompts versus recasts in dyadic interaction. Language Learning, 59(2), 453-498.

Lyster, R., \& Mori, H. (2006). Interactional feedback and instructional counterbalance. Studies in Second Language Acquisition, 28(2), 269-300.

Lyster, R., \& Ranta, L. (1997). Corrective feedback and learner uptake: Negotiation of form in communicative classrooms. Studies in Second Language Acquisition, 19(1), $37-66$.

Lyster, R., \& K. Saito (2010). Oral feedback in classroom SLA: Ameta-analysis. Studies in Second Language Acquisition, 32(2), 265-302.

Lyster, R., Saito, K., \& Sato, M. (2013). Oral corrective feedback in second language classrooms. Language Teaching, 46(1), 1-40.

Maftoon, P., \& Kolahi, S. (2009). The impact of recasts on the syntactic accuracy of Iranian EFL university students' oral discourse. The Journal of Applied Linguistics, 2(2), 160-178.

Rassaei, E. (2015). Journal writing as a means of enhancing EFL learners' awareness and effectiveness of recasts. Linguistics and Education, 32, 118-130.

Saito, K., \& Lyster, R. (2012). Effects of form-focused instruction and corrective feedback on L2 pronunciation development of / I/ by Japanese learners of English. Language Learning, 62(2), 595-633.

Sheen, Y. (2007). The effects of corrective feedback, language aptitude, and learner attitudes on the acquisition of English articles. In A. Mackey (Ed.), Conversational interaction in second language acquisition: a collection of empirical studies (pp. 301322). Oxford: Oxford University Press.

Schmitt, N. (2002). An introduction to applied linguistics. Oxford: Oxford University Press.

Takahashi, N. (2014). Stressed intonation on recasts: Differential effects in comparison with prompts. The Journal of Language Teaching and Learning, 4(2), 15-28.

Trofimovich, P., Ammar, A., \& Gatbonton, E. (2007). How effective are recasts? The role of attention, memory, and analytic ability. In A. Mackey (ed.), Conversational interaction in second language acquisition: A collection of empirical studies (pp. 171195). Oxford, England: Oxford University Press.

Tudor, I. (2001). The Dynamics of the Language Classroom. Cambridge: CUP.

Yang, Y., \& Lyster, L. (2010). Effects of form-focused practice and feedback on Chines EFL learners' acquisition of regular and irregular past tense forms. Studies in Second Language Acquisition, 32(2), 235- 263. 